\title{
Laparoscopic Appendectomy: A Safe and Definitive Solution for Suspected Appendicitis
}

\author{
Joachim Wilfried Heise ${ }^{a} \quad$ Heiner Kentrup ${ }^{b} \quad$ Christoph Gerhart Dietrich ${ }^{c}$ \\ Ansgar Coslerd Dolores Hübner ${ }^{\mathrm{e}}$ Werner Krumholz ${ }^{f}$ \\ ${ }^{a}$ Department of General, Visceral and Thyroid Surgery, Bethlehem Gesundheitszentrum Stolberg (Rhld.), \\ Stolberg, Germany; ${ }^{\mathrm{b}}$ Department of Pediatrics, Bethlehem Gesundheitszentrum Stolberg (Rhld.), \\ Stolberg, Germany; ${ }^{\circ}$ Department of Internal Medicine, Bethlehem Gesundheitszentrum Stolberg (Rhld.),

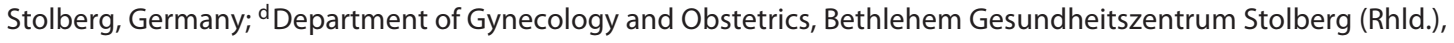 \\ Stolberg, Germany; ${ }^{e}$ Department of Radiology and Pediatric Radiology, Bethlehem Gesundheitszentrum Stolberg \\ (Rhld.), Stolberg, Germany; ${ }^{\mathrm{f} D e p a r t m e n t}$ of Anesthesiology, Bethlehem Gesundheitszentrum Stolberg (Rhld.), \\ Stolberg, Germany
}

\section{Keywords}

Appendicitis · Laparoscopic appendectomy · Morbidity · Complication · Shared decision

\begin{abstract}
Introduction: Since conservative antibiotic treatment in uncomplicated appendicitis might not solve the clinical problem definitively, it has to compete with the results of today's laparoscopic appendectomy. Methods: In a county hospital, accommodating also a pediatric department, all cases of appendectomy for suspected appendicitis over 15 years were analyzed retrospectively for the following items: beginning of symptoms, time from admission to surgery, surgical technique as "open," "laparoscopic" or "converted," if perforated at operation and histological confirmation of acute inflammation. Surgical morbidity was detected in distinct categories. To evaluate changes over time, 3 time periods of 5 years each were defined. Results: Resulting in a total of 1,956 cases there were 731 in group I, 633 in group II and 592 in group III within the 3 time periods, respectively. The median age was 17 years. The percentage of perforations was $16.8 \%$. Those patients had - with 47 compared to $27 \mathrm{~h}$ - a significantly prolonged time from the beginning of symptoms to admission ( $p=0.0001$ ). The proportion of laparoscopic surgery rose from 83.3 (group I) to $98.3 \%$ (group III; $p=0.0001$ ). The median postoperative hospital stay diminished from 4
\end{abstract}

to 3 days in nonperforated ( $p=0.0001$ ) and from 8 to 7 days in perforated cases $(p=0.0009)$. Surgical morbidity was reduced from $4.1 \%$ in the first to $1.7 \%$ in the third observation period ( $p=0.0144$ ). There were no surgical site infections during the last 5 years. Conclusions: Timely laparoscopic appendectomy in case of suspected appendicitis can be offered with an extraordinary low morbidity. Taking into account the complete solution of the otherwise pending threat, compared to conservative antibiotic treatment, it is safe and definitive.

(c) 2020 S. Karger AG, Basel

\section{Introduction}

The question of whether the cause of abdominal pain is appendicitis, including the risk of perforation, arises thousands of times a day all over the world. General practitioners, internists, surgeons, gynecologists and especially pediatricians are involved. The threat of being exposed to an allegation of malpractice due to a misperception is inherent $[1,2]$. Appendicitis presents often very typically but can also mislead the experienced clinician as a symptomatic chameleon [3]. Once the complication of the perforation has been missed, there is a risk of a serious course of the disease, which nowadays still endangers human life and, especially in children, stresses the young patients, 
Table 1. Based on the Alvarado-Score [11] the conditions depicted herein were decisive to call cases presenting with acute abdominal pain "suspected appendicitis" as were those in patients presenting with a prolonged history

Factors promoting assessment as "suspected appendicitis"

\section{Acute cases}

Short history $(<48 \mathrm{~h})$

Pain migration

Nausea or vomiting

Tenderness in the right iliac fossa

Leukocytosis

C-reactive protein elevated

Visible appendix or abscess by sonography

Perityphlitic inflammation in CT scans at age $>50$

\section{Prolonged cases}

Recurrent presentations

Concern of the patient or parents

Pretreating physician

their parents and the nerves of those treating them. Carrying this in mind: can you treat conservatively in case of suspected appendectomy? Recent randomized trials make this appear possible treating solely with intravenous antibiotics [4].

The reason why mostly young adolescents, but also a considerable number of adults up to patients more than 90 years old, develop appendicitis out of complete health has still not been understood until now [5]. Therefore, preventive therapies and those aiming towards a recognized pathogenetic cause are not available. The consequences of a perforation with peritonitis or abscess, which is always threatening by organ destruction, up to the severe, sometimes fatal septic general disease [6], have been treated for more than 130 years by surgical appendectomy [7]. The severity and dynamics of the disease are not always easy to predict at the time of the suspicion and range from simple, perhaps self-limiting, phlegmonous inflammation to gangrenous perforation [8]. At least since the publication of a randomized multicenter study by a Finnish group [4], conservative treatment is seriously discussed. The authors demonstrated that in case of uncomplicated appendicitis, surgery could have been avoided in more than $70 \%$ of patients by sole administration of antibiotics. This raised calls for a better balancing between operation and conservative treatment involving a well-informed patient [9]. A more differentiated handling of such a common clinical question, especially in the children who are affected so often, must of course take into account the most recent results of surgical therapy in appendicitis. The nowadays highly standardized minimally invasive appendectomy published first by the gynecologist Semm [10] introduces a new precondition.
Therefore, the aim of the present study was to provide arguments based on the results of surgery that have been achieved over a period of 15 years. These results ought to support decision-making that is necessary every day in a frequently multidisciplinary context if appendicitis is suspected.

\section{Materials and Methods}

Beginning in August 2001, patients with suspected appendicitis have increasingly undergone laparoscopic surgery in the surgical unit of a county hospital including a pediatric department. Suspicion of appendicitis was raised as outlined in Table 1: in case of acute abdominal pain, especially similar to clinical items of the Alvarado score [11], but also in patients with prolonged and recurrent symptoms and persistent uncertainty. Sonography was helpful, but only decisive by clear results. Since 2004 appendectomy has mainly been done using the minimally invasive technique. Only in the case of children under the age of 6 , in view of the small dimensions, it was decided individually to perform open conventional or minimally invasive surgery, respectively.

\section{Operative Procedures}

Open appendectomy is performed regularly through an alternating incision in the right lower abdomen with skeletonization of the appendix mobilized above the abdominal wall, removal via ligature and an invading suture. For the laparoscopic approach $\mathrm{CO}_{2}$ is inflated above the umbilicus using the Verres needle. After inserting the $12-\mathrm{mm}$ trocar there, another $5-\mathrm{mm}$ trocar is placed suprapubically and a 5- or 10-mm trocar in the left lower abdomen. Thereby an isosceles triangle open to the right is created. With the patient in the Trendelenburg position, the appendix base is then regularly dissected flush with the cecum using a linear stapler $\left(\right.$ Catgut $\left.{ }^{\circledR} 30 \mathrm{~mm}\right)$. The vascular pedicle is interrupted with one or more titanium clips $\left(\right.$ Applied $\left.^{\circledR}\right)$. The specimen is retrieved via the umbilical incision. If the diameter is too large, it may be tailored in situ or extracted in a recovery bag. All appendectomies were performed under single-shot antibiosis with cefuroxime and metronidazole. In complicated cases, the antibiosis was continued postoperatively according to the findings or even broadened by an aminoglycoside.

\section{Data Acquisition}

To evaluate the treatment results achieved under very constant conditions over years, all appendectomies were retrospectively identified from August 2004 to July 2019 over 15 years using the ICD and ICPM coding of the hospital information system (Medi$\mathrm{Co}^{\circledR}$ and Soarian Health Archive - Cerner ${ }^{\circledR}$ ). Only interventions with the indication "suspected appendicitis" were included in the analysis, excluding all concomitant appendectomies as part of other interventions and cases with incomplete data. Six surgical consultants of the department recorded the relevant items into standardized Excel ${ }^{\circledR}$ tables and imported them into a database after being double checked by the first author (FileMaker Pro ${ }^{\circledR} 12.0$ ). In addition to the master data, these were the body measurements, the inflammation values, leukocyte count and C-reactive-protein value, the time from symptom onset to admission ( $\mathrm{S}-\mathrm{A})$, the time from admission to the begin of surgery, the surgical technique (conventionally open, laparoscopically, converted from laparoscopically to open) and the operation time. The histological report of the removed appendix was only designated as "positive" for inflammation if the wording "ulcerative," "periappendicitis" and/or 


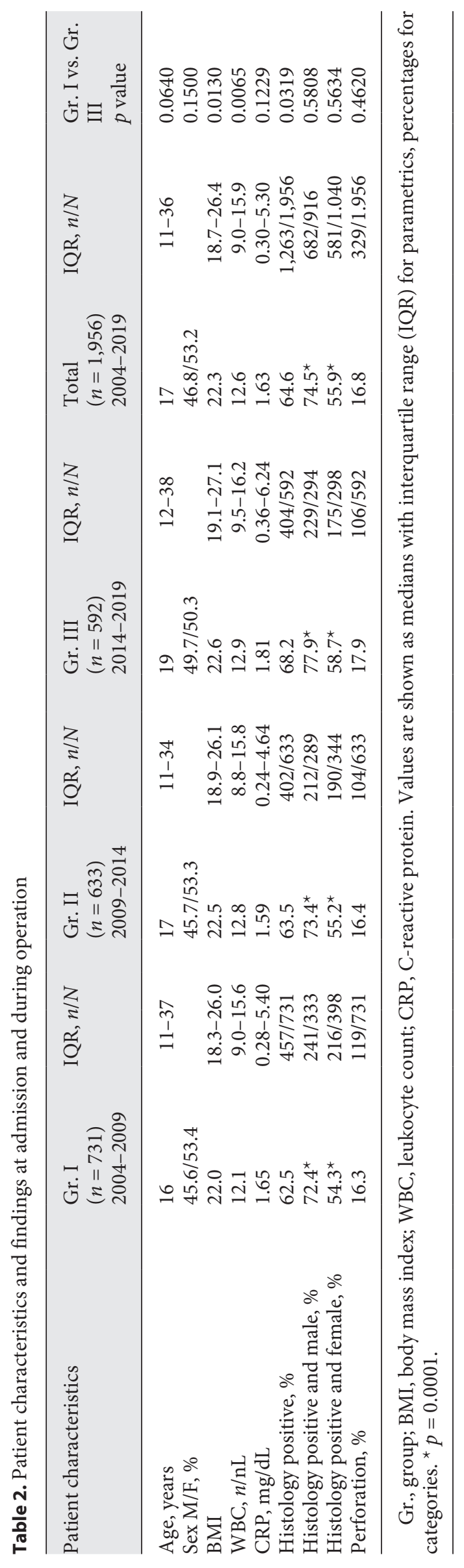

"fibrinous reaction" could be found, otherwise it was called "negative." It was also categorized as "perforation" and "no perforation" based on the operation report, histology and the discharge letter. The latter and remarks in the digital archive were used to evaluate a significant postoperative complication (Clavien-Dindo grade in parenthesis): revisional surgery (IIIb), CT-guided drainage (IIIa), readmission without intervention giving antibiotics (II) and wound healing disorder (IIIa), each instance treated conservatively. In order to evaluate changes of the treatment requirements and the results, the entire observation period was divided into three 5 -year sections resulting in groups I, II and III.

\section{Statistics}

Categorized results are given as percentages, parametric values as medians with interquartile ranges. Statistical comparisons were made for categories using the $\chi^{2}$ test, for continuous parameters using the Mann-Whitney U test (PAST 4.01). A $p$ value of $<0.05$ was considered statistically significant.

\section{Results}

During the observation period from August 1, 2004, to July $31,2019, n=2,112$ appendectomies were performed; after exclusion of accompanying appendectomies $(n=$ $143)$ and cases with missing treatment data $(n=13), n=$ 1,956 patients who had suspected appendicitis had been operated on. These were distributed into the 3 time periods as follows: group I 2004-2009 $(n=731)$, group II 2009-2014 $(n=633)$ and group III 2014-2019 $(n=592)$. The basic patient data are shown in Table 2. Presenting $1,271(65 \%)$ patients $\leq 25$ years, the cohort was dominated by pediatric cases as shown in Figure 1. Concerning the patient characteristics (shown in Table 2), significant changes over time could be recognized in form of an increased body mass index, leukocyte counts and an increased proportion of histologically positive findings. With more female patients over the entire period, there was a highly significant difference for male patients with $74.5 \%$ histologically positive findings compared to female patients with $55.9 \%$ in favor of more positive findings in male patients. At the time of surgery, $16.8 \%$ of all cases had free or covered perforation. With regard to the time span between the S-A, a significantly longer delay was found with ultimately histologically negative findings, but also for cases with perforation (shown in Table 3). The median S-A time of females was significantly longer compared to male patients. In this respect, age and body mass index were irrelevant. The time period S-A is more than twice as long in histologically negative patients compared to those with positive findings. This could express preclinical weighing processes and hidden sex-specific differential diagnoses, for example, ovarian affections in young women. The group of patients with perforation had a significantly longer history of symptoms with $47-$ $27 \mathrm{~h}$ of those not perforated. The time between admission and surgery was not different at 5-6 h, which also indi- 


\section{Age and Sex $(n=1956)$}

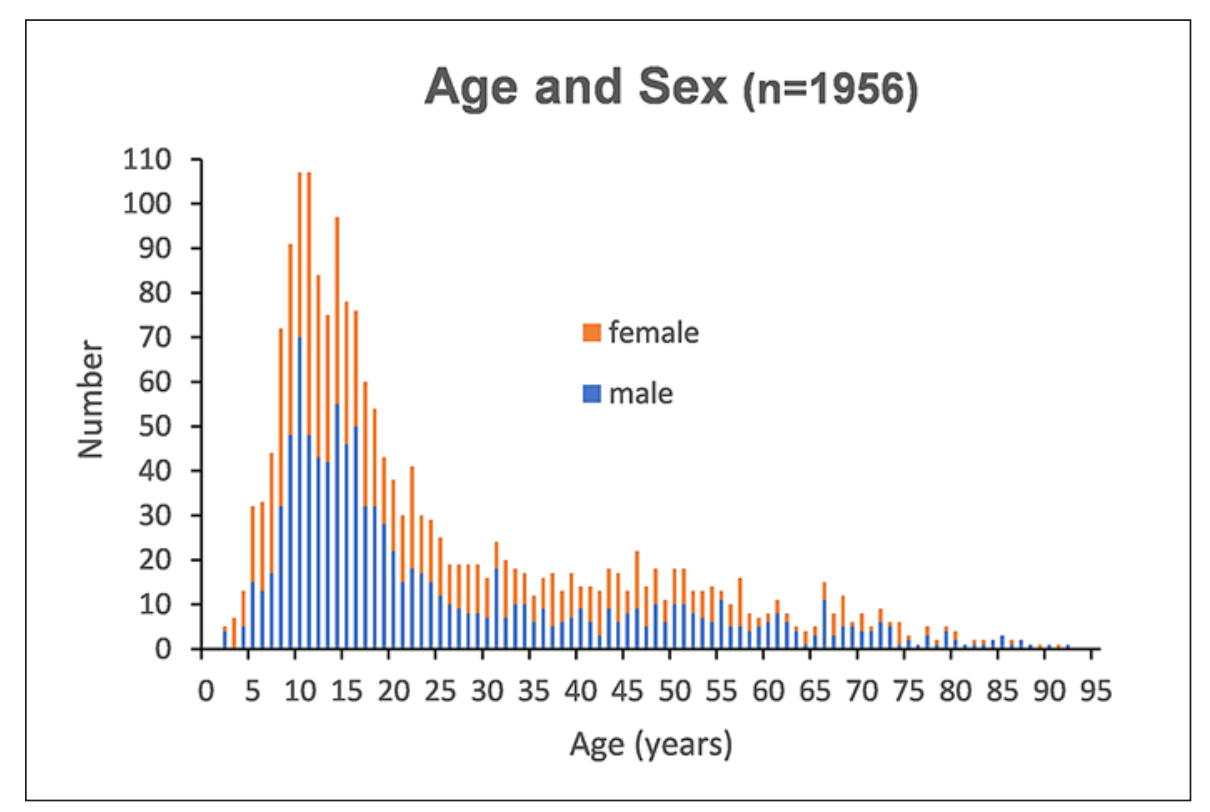

Fig. 1. Age and sex distribution of the whole cohort.

cates that the preclinical decision-making and therefore delay either by the patient or treating physicians potentially could have had a major impact on the seriousness of the disease's course. Patients with later on postoperative complications had somewhat longer S-A and admission-to-surgery times until the intervention, but this did not reach the level of significance.

The laparoscopic surgical approach for appendectomy in our hands has become the standard of care (shown in Table 4). Over the past 5 years, $98.3 \%$ of the patients have had minimally invasive surgery. The operating times in this interval remained at a median of $39 \mathrm{~min}$. Only 2 patients had to be converted from minimally invasive to open surgery. In uncomplicated cases, the postoperative hospital stay was 3 days, after perforation 7 days, respectively. Especially for the uncomplicated cases, there was a significant improvement comparing the first and the current observation period.

There was no mortality. The overall morbidity improved from group I to group III significantly from 4.1 to $1.7 \%$ (shown in Table 5). Considerably fewer reoperations were required in the courses after perforation, but the number of CT-guided drainage placements for intraabdominal abscesses that developed postoperatively remained on a constant level. Particularly noteworthy is the fact that no relevant wound healing disorder was noticed in the last observation period (group III), even in patients after perforation. Within the latest observation period, still 3 invasive interventions postoperatively were necessary in patients without perforation. Of those 2 had advanced and histologically confirmed inflammation. One with histologically negative findings needed relaparoscopy for a relevant intra-abdominal hematoma.

\section{Discussion/Conclusion}

The present retrospective analysis over 15 years provides an authentic picture of a surgically treated group of patients with actual or at least suspected appendicitis. The results achieved are an expression of solving the problem exclusively by an operation. Conservative therapy, as practiced and discussed repeatedly in the literature [4, 12-18], was not applied in our institution within the observation period. In our view, the concept of treating a pathogenetically poorly understood disease only by antibiotic treatment to avoid a bacterial complication must be questioned in principle. To use broad-spectrum antibiotics like ertapenem in uncomplicated appendicitis [8] also seems a violation of nowadays adopted principles of responsible antibiotic stewardship [19]. If one looks at the results achieved with our described surgical strategy, very good results without any mortality are already evident for the cases complicated by perforation, and this with significantly improving morbidity. In this context the CTguided interventional drainage of postoperative abscesses plays an important role, revision procedures were needed less and less. The treatment data of the uncomplicated, that is, nonperforated cases, were impressively positive within the last treatment period. In complicated cases, the consecutive complication rate is pleasingly low in comparison to the literature $[20,21]$, after uncomplicated findings it seems to become negligible. Postoperative hospital stay is short at 3 days, and wound healing disorders have not occurred anymore after surgical procedures of which more than $98 \%$ where minimally invasive within the last 5 years. This means that the results are meanwhile considerably better than achieved in operative groups in 
Table 3. Time periods from start of symptoms to admission (S-A), admission to operation (A-OP) and start of symptoms to operation (S-OP), presented for the whole group and special subgroups as median and interquartile ranges (IQR)

\begin{tabular}{|c|c|c|c|c|c|c|c|}
\hline & $\begin{array}{l}\text { S-A, } \\
\text { h }\end{array}$ & IQR & $\begin{array}{l}\text { A-OP, } \\
\text { h }\end{array}$ & IQR & $\begin{array}{l}\text { S-OP, } \\
\text { h }\end{array}$ & IQR & $p$ value \\
\hline Total $(n=1,956)$ & 28.7 & $13.9-72.2$ & 5.6 & $3.3-18.1$ & 45.4 & $24.6-95.3$ & \\
\hline Histology positive $(n=1,263)$ & 23.9 & $11.9-49.0$ & 4.9 & $3.1-14.2$ & 31.9 & $22.0-58.5$ & $\mathrm{~S}-\mathrm{A} p=0.0001, \mathrm{~A}-\mathrm{OP} p=0.0001$ \\
\hline Histology negative $(n=693)$ & 54.9 & $21.9-159.3$ & 8.5 & $3.7-24.3$ & 75.9 & $33.1-190.3$ & S-OP $p=0.0001$ \\
\hline Perforation $(n=329)$ & 47.1 & $21.6-90.0$ & 5.7 & $3.2-18.1$ & 55.1 & $32.9-104.4$ & S-A $p=0.0001, \mathrm{~A}-\mathrm{OP} p=0.7564$ \\
\hline No perforation $(n=1,627)$ & 26.6 & $12.7-71.7$ & 5.3 & $3.3-18.3$ & 36.5 & $23.4-84.3$ & S-OP $p=0.0001$ \\
\hline Complication $(n=55)$ & 46.6 & $21.0-78.8$ & 8.2 & $3.1-20.6$ & 54.1 & $29.8-121.7$ & S-A $p=0.0559, \mathrm{~A}-\mathrm{OP} p=0.5771$ \\
\hline No complication $(n=1,901)$ & 28.3 & $13.7-72.1$ & 5.6 & $3.3-18.0$ & 43.9 & $24.5-94.8$ & S-OP $p=0.0690$ \\
\hline Male $(n=916)$ & 25.8 & $12.7-57.1$ & 4.9 & $3.0-14.1$ & 34.7 & $22.8-74.7$ & $\mathrm{~S}-\mathrm{A} p=0.0001, \mathrm{~A}-\mathrm{OP} p=0.0001$ \\
\hline Female $(n=1,040)$ & 31.6 & $15.1-81.9$ & 6.9 & $3.4-20.8$ & 51.3 & $26.4-105.1$ & S-OP $p=0.0001$ \\
\hline $\mathrm{BMI} \leq 30(n=1,716)$ & 28.3 & $13.8-72.9$ & 5.6 & $3.2-17.9$ & 43.3 & $24.5-95.7$ & S-A $p=0.3546, \mathrm{~A}-\mathrm{OP} p=0.6841$ \\
\hline $\mathrm{BMI}>30(n=240)$ & 32.2 & $15.6-71.9$ & 5.4 & $3.4-19.4$ & 50.9 & $25.8-82.1$ & S-OP $p=0.3242$ \\
\hline Age $\leq 25$ years $(n=1,271)$ & 28.2 & $13.7-74.2$ & 5.8 & $3.2-18.7$ & 46.1 & $23.8-97.5$ & S-A $p=0.9335, \mathrm{~A}-\mathrm{OP} p=0.4393$ \\
\hline
\end{tabular}

BMI, body mass index; S, symptom; A, admission; OP, operation. $p$ values are calculated for each period comparing within the subgroups.

Table 4. Surgical technique, operation times and resulting postoperative hospital stay as median and interquartile range (IQR)

\begin{tabular}{|c|c|c|c|c|c|c|c|c|c|}
\hline Treatment parameters & $\begin{array}{l}\text { Gr. I } \\
(n=731)\end{array}$ & $n$ & $\begin{array}{l}\text { Gr. II } \\
(n=633)\end{array}$ & $n$ & $\begin{array}{l}\text { Gr. III } \\
(n=592)\end{array}$ & $n$ & $\begin{array}{l}\text { Total } \\
(n=1,956)\end{array}$ & $n$ & $\begin{array}{l}\text { Gr. I vs. } \\
\text { Gr. III } \\
p \text { value }\end{array}$ \\
\hline \multicolumn{10}{|l|}{ Surgical technique, $n$ (\%) } \\
\hline Open & $108(14.8)$ & & $26(4.1)$ & & $8(1.4)$ & & $142(7.3)$ & & 0.0001 \\
\hline Laparoscopic & $609(83.3)$ & & $603(95.3)$ & & $582(98.3)$ & & $1,794(91.7)$ & & 0.0001 \\
\hline Converted & $14(1.9)$ & & $4(0.6)$ & & $2(<0.1)$ & & $20(1.0)$ & & - \\
\hline \multicolumn{10}{|l|}{ Operation time, $\min$} \\
\hline Total & $40(32-52)$ & 731 & $41(31-56)$ & 633 & $39(30-53)$ & 592 & $40(31-54)$ & 1,956 & 0.1062 \\
\hline Open & $40(31-52)$ & 108 & $49(38-65)$ & 26 & $57(42-72)$ & 8 & $42(34-55)$ & 142 & 0.0275 \\
\hline Laparoscopic & $40(31-52)$ & 609 & $41(30-55)$ & 603 & $39(30-52)$ & 582 & $40(30-53)$ & 1,794 & 0.1779 \\
\hline Converted & $75(60-105)$ & 14 & $112(85-169)$ & 4 & $143(92-194)$ & 2 & $89(65-118)$ & 20 & - \\
\hline \multicolumn{10}{|l|}{ Hospital stay, days } \\
\hline Total & $4(3-6)$ & 731 & $3(3-5)$ & 633 & $3(2-5)$ & 592 & $4(3-5)$ & 1,956 & 0.0001 \\
\hline No perforation & $4(3-5)$ & 612 & $3(2-4)$ & 529 & $3(2-4)$ & 486 & $3(3-4)$ & 1,627 & 0.0001 \\
\hline Perforation & $8(6-10)$ & 119 & $6(4-9)$ & 104 & $7(5-9)$ & 106 & $7(5-10)$ & 329 & 0.0090 \\
\hline
\end{tabular}

Gr., group. Hospital stay was assessed especially considering whether perforation was present or not.

studies comparing them with conservative therapy $[4,22$, 23]. In meta-analyses, even very recent ones, surgical complications of appendectomy amounting to almost $20 \%$ are reported [24]. From our point of view this rate is overall too high, especially since this high complication rate in the meta-analyses is often the parameter for a calculated advantage for an equivalency of conservative therapy. This dominance of the surgical complication rate as a decisive factor was also worked out in a decision analysis in which surgical therapy should be preferred as standard if the complication rate is below 11.5\% [25].

Conservatively, patients were initially treated with intravenous-antibiotic inpatient treatment for 3 days, with continued uncertainty about the further course of the disease. Thereafter, $27-46 \%$ of the patients underwent surgery during the following 1-5 years because of an at least suspected disease recurrence $[8,13,14,18,26]$. Leaving the conservatively treated patients in uncertainty whether the disease might strike again obviously results in some kind of appendicitis anxiety described in the literature [27]. In this paper two thirds of the patients with delayed operation after complicated appendicitis wanted to have their appendix removed even without symptoms on the basis of their own request. The open surgical technique that was compared to conservative treatment within the publication of Salminen et al. [4], which is now more than 
Table 5. Surgical morbidity defined as reoperation, interventional treatment by CT-guided drainage, readmission treated conservatively and wound infection treated conservatively

\begin{tabular}{|c|c|c|c|c|c|}
\hline Surgical morbidity & $\begin{array}{l}\text { Gr. I } \\
(n=731)\end{array}$ & $\begin{array}{l}\text { Gr. II } \\
(n=633)\end{array}$ & $\begin{array}{l}\text { Gr. III } \\
(n=592)\end{array}$ & $\begin{array}{l}\text { Total } \\
(n=1,956)\end{array}$ & $\begin{array}{l}\text { Gr. I vs Gr. III } \\
p \text { value }\end{array}$ \\
\hline \multicolumn{6}{|c|}{ All complications, $n(\%)$} \\
\hline Total & $30(4.1)$ & $16(2.5)$ & $9(1.7)$ & $55(2.8)$ & 0.0144 \\
\hline Perforation & $19(2.6)$ & $9(1.4)$ & $6(1.0)$ & $34(1.7)$ & 0.0455 \\
\hline No perforation & $11(1.5)$ & $7(1.1)$ & $3(0.5)$ & $21(1.1)$ & 0.1035 \\
\hline \multicolumn{6}{|l|}{ Reoperations, $n(\%)$} \\
\hline Total & $19(2.6)$ & $8(1.3)$ & $5(0.8)$ & $32(1.6)$ & 0.0213 \\
\hline Perforation & $12(1.6)$ & $4(0.6)$ & $3(0.5)$ & $19(1.0)$ & 0.0648 \\
\hline No perforation & $7(1.0)$ & $4(0.6)$ & $2(0.3)^{*, \#}$ & $13(0.6)$ & 0.1978 \\
\hline \multicolumn{6}{|l|}{ CT drainage, $n(\%)$} \\
\hline Total & $4(0.5)$ & $3(0.5)$ & $4(0.8)$ & $11(0.6)$ & 0.5245 \\
\hline Perforation & $3(0.4)$ & $2(0.3)$ & $3(0.5)$ & $8(0.4)$ & 1.0000 \\
\hline No perforation & $1(0.1)$ & $1(0.2)$ & $1(0.3)^{\S}$ & $3(0.2)$ & 1.0000 \\
\hline \multicolumn{6}{|c|}{ Readmission treated conservatively, $n(\%)$} \\
\hline Total & $3(0.4)$ & $2(0.3)$ & $0(0)$ & $5(0.3)$ & 0.2634 \\
\hline Perforation & $2(0.3)$ & $1(0.2)$ & $0(0)$ & $3(0.2)$ & 0.5013 \\
\hline No perforation & $1(0.1)$ & $1(0.1)$ & $0(0)$ & $2(0.1)$ & 1.0000 \\
\hline \multicolumn{6}{|c|}{ Wound infections treated conservatively, $n(\%)$} \\
\hline Total & $4(0.5)$ & $3(0.5)$ & $0(0)$ & $7(0.4)$ & 0.1327 \\
\hline Perforation & $3(0.4)$ & $2(0.3)$ & $0(0)$ & $5(0.3)$ & 0.2634 \\
\hline No perforation & $1(0.1)$ & $1(0.2)$ & $0(0)$ & $2(0.1)$ & 1.0000 \\
\hline
\end{tabular}

Three patients of group (Gr.) III presenting postoperative morbidity without having had perforation. * Relaparoscopy because of intra-abdominal hemorrhage without active bleeding at that time (histology negative).

\# Relaparoscopy after a retrocolic ulcerative appendicitis presenting a hematoma. ${ }^{\S} \mathrm{CT}$-guided drainage following gangrenous appendicitis.

5 years ago, is no longer state of the art at least in Germany [21]. This is highlighted above all in an American collective study which, with also a $98 \%$ rate of minimally invasive interventions and a routine hospital stay of around $24 \mathrm{~h}$ postoperatively, is openly questioning the conservative treatment approach in Europe [26].

Having experienced once the sometimes very demanding course in children after perforation that has been overlooked because of misleading symptoms in the beginning like diarrhea, for example, one has to ask whether the risk of such incidents caused by delayed appendectomy is acceptable, especially facing the extremely low complication rate of the laparoscopic approach. Given the results presented herein, further on it might be discussed how intensively we have to promote an open shared decision-making process involving patients, especially children and their often emotionalized parents, as it is advocated in the literature $[9,28]$. There are numerous publications targeting the goal to support the decision-making process by scoring systems. In our retrospective study a score like that of Alvarado [11,28] was not applicable because not all parameters would have been available. Just recently Bhangu et al. [29] presented results applying 2 scores in 154 UK hospitals and proposed thereby to reduce the number of so-called normal appendectomies. Considering the fact that histological findings after appendectomies are debatable on what is diseased or not [30], evaluation of those scores might be of help but they are not always suitable to decide about whether to operate under the very individual circumstances or not. In our view, if there is sufficient clinical suspicion, conviction of an experienced surgeon combined with the perception of uncertainty unsettling the patient or its accompanying people, it is justified to give the definite and firm advice to solve the pending problem by a nowadays low-risk laparoscopic operation. The preclinical latencies obviously play a significant role for the initial severity of the case and the postoperative course in the present study and in others [31,32]. The risk of a definite decision in favor of a surgical procedure actually appears almost to be negligible.

Round about one third of our patients have shown no convincing histopathological signs of inflammation. This might raise concern that too much healthy organs could have been removed being responsible for good results. One reason for that number we see in the very strict definition of relevant inflammation excluding pathological descriptions like, for example, "catarrhal" or "exudative" which might be counted as positive histology by others. Another reason for more "negative appendectomies" 
could be seen in a certainly more active philosophy to resolve the disturbing clinical problem of unknown pain in the lower right quadrant including, for example, young women, in whom the gynecologist did not take responsibility and a nonnecrotic appendix was removed after having found a ruptured ovarian cyst during explorative laparoscopy.

In our view there is no doubt about tailoring the indication for appendectomy on one side according to the key factors listed in Table 1 but on the other side respecting the preconditions of the individual patient including its social surrounding. Suspected appendicitis in pregnancy is a rare but from time to time inevitably upcoming problem. We experienced 2 cases: one perforated in the 36th week was resolved by early sectional delivery, the other ulcerophlegmonous case was laparoscopically operated in week 22. Are there significant and even progressive symptoms when appendectomy is mandatory, the type of execution depends on the level of the uterine fundus.

The comparison of open surgery appendectomy versus a minimally invasive procedure, which is still considered in current meta-analyses [33, 34], appears to be no relevant question any more looking to our own results and the status quo in Germany [20]. As mentioned above in the USA $[26,35]$ there is a very high frequency of minimally invasive appendectomies and no one really wants to dispense with the advantages of full diagnostic laparoscopy especially in surgical units where laparoscopic procedures are meanwhile by far more frequent than open ones. The technique of sealing the appendix stump exclusively by a stapler device is highly standardized and apparently very safe. Discussions about this are basically only kept open by economic aspects [36, 37].

In our opinion, the diagnosis of suspected appendicitis is based on the precise evaluation of the case history. A short-term illness with lower abdominal pain out of complete health is a particularly important argument $[5,26]$. The standard laboratory values for white blood cell count and C-reactive protein should then be related to the duration of symptoms (S-A). With a history of just hours, leukocytosis with a (still) low C-reactive protein value is typical for surgically relevant appendicitis. A low white blood cell count combined with a longer latency period $>48-72$ $\mathrm{h}$ makes relevant appendicitis not only in our view very unlikely [38]. Abdominal sonography may be helpful if the appendix can be displayed [39] and appears to be indispensable, especially in children. A CT of the abdomen is meanwhile surprisingly ubiquitous and well established in adults and especially older patients over the age of 50 and with a risk profile $[40,41]$. The native $\mathrm{CT}$ is available in many ways in a targeted and particularly uncomplicated manner. Contrast enhancement can even differentiate between moderate and gangrenous forms of appendiceal inflammation [42].
In contrast to the USA [41], in Europe, following the philosophy of a strictly targeted and patient-oriented decision-making, a determination in terms of a surgical approach can be achieved in most cases even without CT [5] by means of the case history, abdominal findings (peritonism), laboratory data and sonography.

Given the extremely low morbidity, especially in the case of uncomplicated appendicitis, the experienced surgeon operating laparoscopically on a daily basis may now advocate an obviously very safe appendectomy if there is a substantial degree of suspicion of appendicitis. Thereby he will limit the existing uncertainty and the fear for perforation which still dominates the thoughts on appendicitis amongst the public. With a postoperative hospital stay of often only 2 days and the $100 \%$ avoidance of an otherwise possibly complicated course that cannot be excluded by other means, this appears to be really good clinical practice. Thus, in individual cases, it is even useful to consider that long-term undecided cases might be brought to an end in the sense of a definitive solution of the question whether an underlying appendicitis is relevant by a socalled "conceptual appendectomy." The removal of a macroscopically rather inconspicuous appendix in such instances is a quite common and acceptable practice in the literature [43]. Laparoscopic appendectomy is therefore a safe and definitive treatment option in the best sense.

\section{Conclusion}

In the present unicentric retrospective study almost 2,000 patients of all ages with suspected appendicitis underwent appendectomy over a period of 15 years, this with increasing frequency by a laparoscopic approach. Given one third of histopathologically not significantly inflamed appendices, there was no mortality and surgical morbidity was very low, especially within the last 5 years. This applies particularly to uncomplicated cases but also to patients with perforation. Accordingly, in the case of acute and recurrent lower abdominal pain and suspected appendicitis, we would advocate for an early laparoscopic appendectomy. Facing the currently achieved results, a more offensive indication seems justifiable even with chronically recurrent complaints. The option of initially conservative treatment with antibiotics compared to a minimally invasive operation clearly takes a back seat in view of the safe and definitive solution to the problem reached by laparoscopic surgery.

\section{Acknowledgment}

On behalf of the first author, this work is dedicated to my clinical and academic teacher for more than 20 years, em. Prof. Dr. med. Hans-Dietrich Röher (Heinrich Heine University Düssel- 
dorf), who taught me that surgery is more than operating people but always to reflect on the achieved results in a systematic approach. This attitude represents the very special responsibility for our entrusted patients. We all together are thankful to the involved surgical colleagues and members of the hospital administration, who retrieved the raw data from the clinical information system. We could not have made the decisions of positive or negative appendectomy without the pathology reports created by the Pathological Institute of the RWTH Aachen (Prof. Dr. R. KnüchelClarke).

\section{Statement of Ethics}

Not necessary as within this retrospective study no personalized data were exposed to other than the reviewing physicians.

\section{Disclosure Statement}

The authors have no conflicts of interest to declare.

\section{Funding Sources}

There has been no funding from other institutions.

\section{Author Contributions}

The participating authors were each responsibly involved in all aspects of the daily treatment decisions and treatment itself of the evaluated patients within our institution. Additionally, they were working on and correcting the paper on behalf of their clinical specialties.

\section{References}

1 Krukemeyer MG, Pflugmacher I, Püschel K. Die forensischen Aspekte bei tödlichem Ausgang einer akuten Appendizitis. Zentralbl Chir. Dec;130(6):594-6.

2 Choudhry AJ, Anandalwar SP, Choudhry AJ, Svider PF, Oliver JO, Eloy JA, et al. Uncovering malpractice in appendectomies: a review of 234 cases. J Gastrointest Surg. 2013 Oct; 17(10):1796-803

3 Mahajan P, Basu T, Pai CW, Singh H, Petersen N, Bellolio MF, et al. Factors associated with potentially missed diagnosis of appendicitis in the emergency department. JAMA Netw Open. 2020 Mar;3(3):e200612.

4 Salminen P, Paajanen H, Rautio T, Nordström P, Aarnio M, Rantanen T, et al. Antibiotic therapy vs appendectomy for treatment of uncomplicated acute appendicitis: the APPAC randomized clinical trial. JAMA. 2015 Jun;313(23):2340-8.

5 Bhangu A, Søreide K, Di Saverio S, Assarsson JH, Drake FT. Acute appendicitis: modern understanding of pathogenesis, diagnosis, and management. Lancet. 2015 Sep; 386(10000):1278-87.

6 Kern E. Sehen - Denken - Handeln eines Chirurgen im 20. Jahrhundert. ecomed, Landsberg am Lech; 2000, p. 202.

7 Schmiedebach HP, Winau R, Häring R, editors. Erste Operationen Berliner Chirurgen 1817-1931. Berlin, New York: Walter de Gruyter; 1990. p. 10.

8 Ohmann C, Franke C, Kraemer M, Yang Q. [Status report on epidemiology of acute appendicitis]. Chirurg. 2002 Aug;73(8):769-76.

9 Gießelmann K. Appendektomie kein Muss. Dtsch Arztebl. 2018;115(31-32):A1438-40.

10 Semm K. Endoscopic appendectomy. Endoscopy. 1983 Mar;15(2):59-64.

11 Alvarado A. A practical score for the early diagnosis of acute appendicitis. Ann Emerg Med. 1986 May;15(5):557-64.

12 Sceats LA, Trickey AW, Morris AM, Kin C, Staudenmayer KL. Nonoperative management of uncomplicated appendicitis among privately insured patients. JAMA Surg. 2019 Feb;154(2):141-9.

13 Salminen P, Tuominen R, Paajanen H, Rautio T, Nordström P, Aarnio M, et al. Five-year follow-up of antibiotic therapy for uncomplicated acute appendicitis in the APPAC randomized clinical trial. JAMA. 2018 Sep; 320(12):1259-65.

14 Sippola S, Haijanen J, Viinikainen L, Grönroos J, Paajanen $\mathrm{H}$, Rautio T, et al. Quality of life and patient satisfaction at 7-year followup of antibiotic therapy vs appendectomy for uncomplicated acute appendicitis: a secondary analysis of a randomized clinical trial. JAMA Surg. 2020 Feb;155(4):283.

15 Maita S, Andersson B, Svensson JF, Wester T. Nonoperative treatment for nonperforated appendicitis in children: a systematic review and meta-analysis. Pediatr Surg Int. 2020 Mar;36(3):261-9.

16 Sallinen V, Akl EA, You JJ, Agarwal A, Shoucair S, Vandvik PO, et al. Meta-analysis of antibiotics versus appendicectomy for non-perforated acute appendicitis. Br J Surg. 2016 May;103(6):656-67.

17 Schölch S, Reißfelder C. [Antibiotic treatment vs. appendectomy for non-perforated appendicitis in adults]. Chirurg. 2019 Mar;90(3): 178-82.

18 Patkova B, Svenningsson A, Almström M, Eaton S, Wester T, Svensson JF. Nonoperative treatment versus appendectomy for acute nonperforated appendicitis in children: fiveyear follow up of a randomized controlled pilot trial. Ann Surg. 2020 Jun;271(6):1030-35.

19 Leeds IL, Fabrizio A, Cosgrove SE, Wick EC. Treating wisely: the surgeon's role in antibiotic stewardship. Ann Surg. 2017 May;265(5): 871-3.

20 Sahm M, Pross M, Otto R, Koch A, Gastinger I, Lippert H. Clinical health service research on the surgical therapy of acute appendicitis: comparison of outcomes based on 3 german multicenter quality assurance studies over 21 years. Ann Surg. 2015 Aug;262(2):338-46.

21 Andert A, Alizai HP, Klink CD, Neitzke N, Fitzner C, Heidenhain C, et al. Risk factors for morbidity after appendectomy. Langenbecks Arch Surg. 2017 Sep;402(6):987-93.

22 Flum DR. Clinical practice. Acute appendicitis-appendectomy or the "antibiotics first" strategy. N Engl J Med. 2015 May;372(20): 1937-43.
23 Yeh DD, Sakran JV, Rattan R, Mehta A, Ruiz $\mathrm{G}$, Lieberman $\mathrm{H}$, et al. A survey of the practice and attitudes of surgeons regarding the treatment of appendicitis. Am J Surg. 2019 Jul; 218(1):106-12.

24 Yang Z, Sun F, Ai S, Wang J, Guan W, Liu S. Meta-analysis of studies comparing conservative treatment with antibiotics and appendectomy for acute appendicitis in the adult. BMC Surg. 2019 Aug;19(1):110.

25 Bolger JC, Kelly ME, Barry K. Acute appendicitis in the adult population: modelled decision analysis supports a conservative approach. J Gastrointest Surg. 2015 Dec;19(12): 2249-57.

26 Yeh DD, Eid AI, Young KA, Wild J, Kaafarani HM, Ray-Zack M, et al.; EAST Appendicitis Study Group. Multicenter study of the treatment of appendicitis in america: acute, perforated, and gangrenous (MUSTANG), an EAST multicenter study. Ann Surg. 2019. Doi: 10.1097/SLA.0000000000003661.

27 Shekarriz S, Keck T, Kujath P, Shekarriz J, Strate T, Keller R, et al. Comparison of conservative versus surgical therapy for acute appendicitis with abscess in five German hospitals. Int J Colorectal Dis. 2019 Apr;34(4):64955.

28 Kyaw L, Pereira NK, Ang CX, Choo CS, Nah SA. Parental preferences in treatment of acute uncomplicated appendicitis comparing surgery to conservative management with antibiotics and their views on research participation. Eur J Pediatr. 2020 May;179(5):735-42.

29 Bhangu A; RIFT Study Group on behalf of the West Midlands Research Collaborative. Evaluation of appendicitis risk prediction models in adults with suspected appendicitis. $\mathrm{Br} \mathrm{J}$ Surg. 2020 Jan;107(1):73-86.

30 van den Boom AL, de Wijkerslooth EM, Mauff KA, Dawson I, van Rossem CC, Toorenvliet BR, et al. Interobserver variability in the classification of appendicitis during laparoscopy. Br J Surg. 2018 Jul;105(8):10149.

31 Westfall KM, Charles AG. Risk of perforation in the era of nonemergent management for acute appendicitis. Am Surg. 2019 Nov; 85(11):1209-12. 
32 Papandria D, Goldstein SD, Rhee D, Salazar JH, Arlikar J, Gorgy A, et al. Risk of perforation increases with delay in recognition and surgery for acute appendicitis. J Surg Res. 2013 Oct;184(2):723-9.

33 Fujishiro J, Watanabe E, Hirahara N, Terui K, Tomita H, Ishimaru $\mathrm{T}$, et al. Laparoscopic versus open appendectomy for acute appendicitis in children: a nationwide retrospective study on postoperative outcomes. J Gastrointest Surg. 2020. Doi: 10.1007/s11605-02004544-3.

34 Jaschinski T, Mosch CG, Eikermann M Neugebauer EA, Sauerland S. Laparoscopic versus open surgery for suspected appendicitis. Cochrane Database Syst Rev. 2018 Nov; 11:CD001546.

35 Dumas RP, Subramanian M, Hodgman E, Arevalo M, Nguyen G, Li K, et al. Laparoscopic appendectomy: a report on 1164 operations at a single-institution, safety-net hospital. Am Surg. 2018 Jun;84(6):1110-6.
36 Kim S, Weireter L. Cost effectiveness of different methods of appendiceal stump closure during laparoscopic appendectomy. Am Surg. 2018 Aug;84(8):1329-32.

37 Clement KD, Emslie K, Maniam P, Wilson MS. What is the operative cost of managing acute appendicitis in the NHS: the impact of stump technique and perioperative imaging. World J Surg. 2020 Mar;44(3):749-54.

38 Kashtan M, Graham D, Anandalwar S, HillsDunlap J, Rangel S. Influence of symptom duration and WBC profile on the negative predictive value of a nondiagnostic ultrasound in children with suspected appendicitis. J Pediatr Surg. 2020 Jun;55(6):1032-6.

39 Tyler PD, Carey J, Stashko E, Levenson RB, Shapiro NI, Rosen CL. The potential role of ultrasound in the work-up of appendicitis in the emergency department. J Emerg Med. 2019 Feb;56(2):191-6.

40 Sippola S, Virtanen J, Tammilehto V, Grönroos J, Hurme $S$, Niiniviita $\mathrm{H}$, et al. The accu- racy of low-dose computed tomography protocol in patients with suspected acute appendicitis: the OPTICAP study. Ann Surg. 2020 Feb;271(2):332-8.

41 Cuschieri J, Florence M, Flum DR, Jurkovich GJ, Lin P, Steele SR, et al.; SCOAP Collaborative. Negative appendectomy and imaging accuracy in the Washington State Surgical Care and Outcomes Assessment Program. Ann Surg. 2008 Oct;248(4):557-63.

42 Elbanna KY, Mohammed MF, Chahal T, Khosa F, Ali IT, Berger FH, et al. Dual-energy $\mathrm{CT}$ in differentiating nonperforated gangrenous appendicitis from uncomplicated appendicitis. AJR Am J Roentgenol. 2018 Oct; 211(4):776-82.

43 Logie K, Robinson T, VanHouwelingen L. Management of the normal-appearing appendix during laparoscopy for clinically suspected acute appendicitis in the pediatric population. J Pediatr Surg. 2020 May;55(5): 893-8. 